
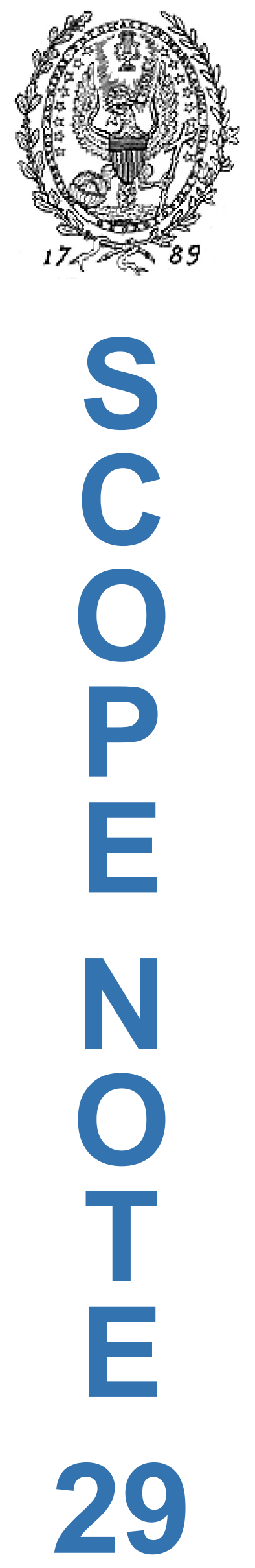

Bioethics Research Library

The Joseph and Rose Kennedy Institute of Ethics

Box 571212, Georgetown University

Washington, DC 20057-1212

202-687-3885; fax: 202-687-8089

bioethics@georgetown.edu

http://bioethics.georgetown.edu

\title{
Organ Transplant Allocation
}

\author{
Pat Milmoe McCarrick \\ Revised January, 1996
}

The introduction of the antibiotic, cyclosporin, which enhances the success rate of transplantation surgery, has resulted in the steady growth of organ transplantation since the mid-1980s. This growth increasingly focuses ethical interest on both the procurement and the allocation of human organs. Not everyone who might benefit from organ transplants can receive them since the number of patients in need of organs far exceeds the number of organs available. Each year the waiting list for transplants increases by 20 percent, but the number of donated organs has remained stable for the past five years (Lawry 1994, p. 9).

Organ transplantation surgery performed on rock stars, sports heroes, politicians, and television celebrities brings questions about the fair allocation of scarce resources to the attention of everyone. Abigail Trafford, editor of Washington Post Health, wonders whether "new livers for hard livers" can be deserved when not enough organs are available for everyone who needs them. Writing about the dilemma of just allocation of organs, she calls famous recipients "poster patients" or "health care celebrities of medical catastrophe" (Trafford 1994, p. 13). Personal responsibility - the viewpoint that "medical treatment should not be an entitlement program for profligate living - is an emerging moral consideration according to Trafford. Deciding whose standards and values should apply to the allocation of organs raises many questions. Popular arguments for keeping the current criteria for allocation include: 


\section{TABLE OF CONTENTS}

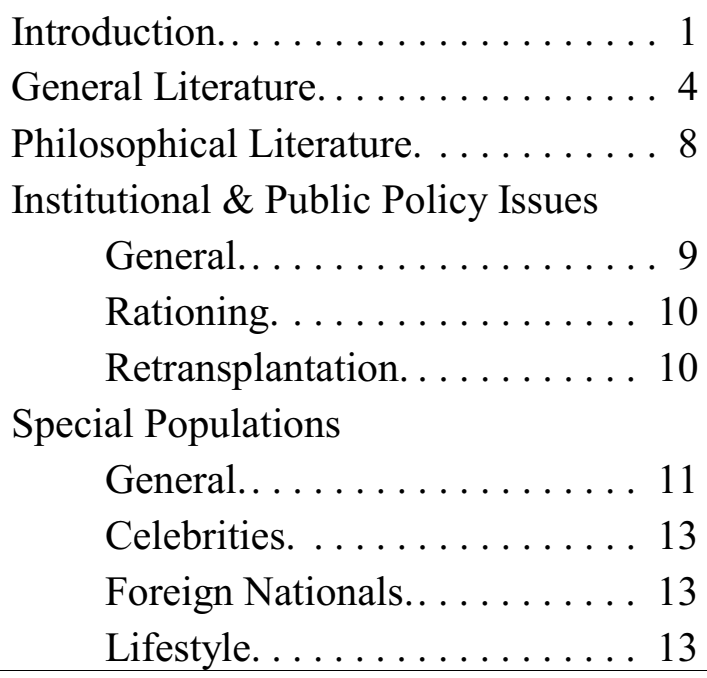

these patients are sick and therefore should be treated, regardless of the cause of their illness; former substance abusers should be able to benefit from their present abstention; physicians should treat anyone who is ill; and although many human illnesses may be caused by individual behavior, such behavior is not always used as a reason to deny care (Trafford 1995, p. 12).

Prior to 1984, when the government established regulations governing organ transplantation, organs routinely were given to the patients of the surgeons who excised them (Prottas 1994, p. 9). In an effort to achieve a more equitable method, Congress passed the National Organ Transplant Act of 1984 (Pub. L. No. 98-507, amended by Pub. L. No. 100-607 and Pub. L. No. 101-616), which established a national Organ Procurement and Transplantation Network (OPTN) to improve the effectiveness of organ procurement, organ distribution, and transplant activities. The United Network for Organ Sharing (UNOS) received the federal government contract to be the OPTN.

UNOS and its 66 regional organ procurement organizations (OPOs) around the nation have carried out the mandate since 1986. It requires hospitals that receive Medicare or Medicaid funds and perform transplants to belong to the network and to allocate organs according to network policies. UNOS maintains the national computer regis-try to match donor organs with individual recipients. In distributing organs, UNOS is re- quired by law to use a fair and equitable system based on accepted medical criteria. UNOS regularly reevaluates its policies to ensure that organ donation and recipient selection meet criteria of efficiency and equity (UNOS Update 11(8), 1995, p. 7).

At the end of June 1995, 278 transplant centers were in operation in the United States: almost all of them (247 centers) transplanted kidneys; 167 did hearts; 119, pancreases; 114, livers; 93, heartlung; 88 , lungs; 26, intestines; and only 19 centers performed pancreas islet cell transplants (UNOS Update 11(8): 28, 1995, p. 7). The number of patients waiting for organ transplants in July 1995 totalled 41,075: 29,274 were waiting for a kidney transplant; 4,937, liver; 3,298, heart; 1,816, lung; 1,223 kidney-pancreas; 240, pancreas; and 211, heart-lung (UNOS Update 11(8): 40-41, 1995, p. $7)$.

OPOs are located in different geographic areas across the country, each with different organ needs or lengths of waiting lists, or with lists in areas where large, older populations make it more difficult to find suitable donors. Black recipients often wait longer due to complex reasons including sensitization or rarer blood and antigen types (UNOS 11(8): 31-32, 1995, p. 7). When an organ becomes available, the OPO involved identifies a potential recipient from the UNOS list and offers it to the patient's surgeon. If no match can be made locally, the organ is next offered within a UNOS region, and finally, to the entire nation (Margolis 1993, p. 9).

Some have criticized local and regional lists and favor instead a combination, local-national listing which might first allocate organs within a region, but would also look at the whole nation to achieve fairer and more efficient distribution utilizing policies consistent across regions (Feiden and Rogut 1992). Ethical dilemmas about foreign nationals seeking organ transplantation in the United States resulted in federal regulations to restrict such transplants that are similar to the UNOS guidelines concerning non-resident aliens (Federal Register (53): 8977, 18 March 1988).

Human organs are only suitable for transplantation for a limited period of time following deathkidneys are usable only for 72 hours. In prepara- 
tion for transplantation, potential organ recipients are pre-tested for blood type, tissue type, and blood antibodies. This information is then placed persons accumulate points based on tissue match, sensitization, time spent on the list, and age.

UNOS considerations for allocation include, depending on the organ, length of waiting time, appropriate medical and scientific criteria, which are publicly stated, and equitable access without favoritism, political influence, or discrimination based on race, sex, or financial advantage (UNOS 1994, p. 9).

Implemented or suggested changes in allocation principles include: prohibiting a person from being on several waiting lists simultaneously (Miller 1992, p. 6), increasing priority for children on waiting lists, ensuring fairness in queuing for the lists, and developing guidelines to determine admission to the waiting lists. Childress states that while it may not be possible to give equal weight to every principle, UNOS is right to stress the injustice that can result when only one factor becomes determinative in the selection process (Childress 1995, p. 8). A recent doctoral thesis dis-cusses eight ways that organs might be allocated. The author recommends that only persons who are willing to donate organs should be eligible to receive organ transplants, a method called "modified altruistic reciprocity" (Booker 1991, p. 7). A similar suggestion appears in the August 1995 issue of the Journal of Medical Ethics: admission to transplant lists would be conditioned on registration as a potential donor (Jarvis 1995, p. 5).

The American Medical Association's Council on Ethical and Judicial Affairs suggests the use of medical criteria in the allocation of scarce organs, including: "(1) the likelihood of benefit to the patient, (2) the impact of treatment in improving the quality of the patient's life, (3) the duration of the benefit, (4) the urgency of patient's condition (i.e., how close the patient is to death), and in some cases (5) the amount of resources required for successful treatment." Inappropriate criteria would include ability to pay, the contribution of the patient to society, perceived obstacles to treatment, contribution of the patient to his or her own medical condition, and the patient's past use of health care resources. When all criteria have been considered, "maximizing the number of lives saved should generally take priority over other goals, as long as the patients saved would not suffer an extremely poor quality of life or extremely short duration of benefit." When all else is equal, a "first-come, first-served approach or some other equal-opportunity mechanism should be employed" (American Medical Association 1993, p. 8). This AMA position is seen by many to be at odds with the federal requirement that equity be given consideration equal to efficiency in maximizing the number of lives saved.

Although the reasons are uncertain (perhaps later diagnosis or treatment refusal), statistics show that in cardiac transplantation worldwide, many more men than women receive heart transplants: in 1992 males received 81 percent of the hearts transplanted (Randall 1993, p. 11). Kjellstrand and Dossetor (1992, p. 5) say that "in general, men have been 'preferred' as patients for treatment before women, the rich are favoured over the poor, and even in the most supposedly 'egalitarian' systems power leaps to the fore." A recent Hastings Center Report discusses four court decisions concerning organ allocation when various patients had been denied treatment based on their lack of ability to pay, either via Medicaid or private insurance plans (Moskowitz 1995, p. 9).

Two well-known social scientists, Renée C. Fox and Judith P. Swazey (1993, p. 8), have raised important questions about the wisdom of continuing the entire organ transplantation program in the United States. Concerned about the amount of professional and public consideration given to transplantation, they ask whether all organ transplant activities "divert attention and human and financial resources away from more basic and widespread public and individual health care needs in our society."

Retransplantation of persons who have already received an organ or organs raises questions of allocation fairness. Since there are not enough organs for all who are waiting, should some patients have several opportunities to regain health when others have not yet had any chance? Retransplantation is often recommended by surgical teams whose ongoing relationship with a particular patient increases their involvement and whose statistics suggest that retransplantation is 
surgically successful (Delmonico et al. 1994, p. 10). On the other hand, Paul Menzel (1994, p. 6) asks "Can't we count?" pointing out that if one child receives seven organs, seven others receive none. Collins and Mozdzierz (1993, p. 10) recommend that each person only have one transplant based upon their observation of low survival statistics in persons who are retransplanted. The UNOS Ethics Committee has rejected these arguments pointing to technical and ethical factors supporting the claim that retransplant should not be a relevant consideration in allocating organs.

\section{GENERAL LITERATURE}

Annas, George J. The Prostitute, the Playboy, and the Poet: Rationing Schemes for Organ Transplantation. American Journal of Public Health 75(2): 187-89, February 1985.

Describing 1960s meetings and decisions of the anonymous Seattle kidney screening committee, Annas says their biases and selection criteria for allocating cadaver kidneys were criticized as being too arbitrary. He presents four major approaches to allotting scarce resources: the market approach (an organ to anyone who can pay for it), which he thinks shows a lack of fairness and equity; the committee selection process, which he says will always fail because certain members will prefer some over others; the lottery approach (the "ultimate equalizer"), a mindless method that undermines the pricelessness of life; and the customary approach, decisions that are not explicitly acknowledged and are therefore tolerable. He urges a combination wherein the initial screening process is based on objective medical criteria reviewed by an ethics committee with public representation. Organs would then be allocated on a first-come, first-served basis. In addition, Annas thinks that some individuals would voluntarily opt not to join the pool when presented with the side effects of transplantation prior to medical screening, thereby reducing waiting lists and lowering costs.

Caplan, Arthur L. Equity in the Selection of Recipients for Cardiac Transplants. Circulation 75(1): 10-19, January 1987.

Caplan cites criticism applied to the selection of adult recipients of transplants, including commercialism, psychosocial factors, discrimina- tion, and distribution equity. Cardiac transplantation seems exempt from these criticisms, he says, perhaps as a reflection of the public receiving more information than in the past.

Caplan, Arthur L. If I Were a Rich Man Could I Buy a Pancreas? Problems in the Policies and Criteria Used to Allocate Organs for Transplantation in the United States. In If I Were a Rich Man Could I Buy a Pancreas? and Other Essays on the Ethics of Health Care, pp. 158-77. Bloomington, IN: Indiana University Press, 1992. Saying society's support for transplantation is fragile, Caplan points out that news stories about people using publicity to obtain access to transplants encourage the public view that the process is unfair. He thinks there should be public debate to review policy and to "hold those who use them accountable." He sees the process as a "funnel of organ allocation" with persons in need of organs at the wide top, a narrowing down by the ability to obtain admission to a transplant center, followed by the distribution of available organs among various transplant centers, and finally selection of a particular recipient.

Childress, James F. Who Shall Live When Not All Can Live? Soundings 53(4): 339-55, Winter 1970.

In this early work, Childress favors randomness or chance in organ allocation: either first come, first served or a lottery. He thinks that a social worth selection process decreases patient trust and violates the patient's status as a person.

Cohen, B., and D'Amaro, J. Some Contemporary Ethical Considerations Related to Organ Transplantation. Transplant International 8(3): 238-43, 1995.

The increasing number of transplants creates new ethical dilemmas related to the fair allocation of organs, according to the authors, who recommend use of alternative sources of donor organs. They urge that allocation priorities be defined by society as a whole.

Corley, M. C., and Sneed, G. Criteria in the Selection of Organ Transplant Recipients. Heart and Lung 23(6): 446-57, November- December 1994.

The authors describe the criteria for selection of 
heart, lung, liver, pancreas, and kidney transplant recipients, noting similarities and differences, and review proposed approaches in allocating these scarce organs. They conclude that selection (other than medical criteria applied to the diseased organ) varies by region and by organ with "no universal system ... to guide recipient selection."

Cravan, John, and Rodin, Gary M. Psychiatric Aspects of Organ Transplantation. New York: Oxford University Press, 1992. 243 p.

The collection of essays discusses such topics as candidate assessment, outcome prediction, social support, religious and spiritual perspectives, ethical considerations, and psychiatric aspects for recipients of specific organs.

Edwards, Barba Jean. Ethical Considerations in Organ Transplantation. Seminars in Perioperative Nursing 1(1): 33-36, January 1992.

Edwards compares the growth of organ transplantation with the parallel emergence of general bioethics, discussing ethical and moral issues brought forth by this technology.

Evans, Roger W. Organ Transplantation and the Inevitable Debate As to What Constitutes a Basic Health Care Benefit. In Clinical Transplants, ed. Paul Teresaki and J. M. Cecka, pp. 359-91. Los Angeles: UCLA Tissue Typing Laboratory, 1993.

The need for health care reform is an "economic reality," according to Evans, who recommends that patient selection policies be reconsidered. He states that patients least likely to benefit and costing the most are given priority. Evans calls this a clinically indicated approach that is "socially unacceptable." The allocation of organs to recipients who would benefit most needs to be consistent with the "principles of cost effectiveness."

Fabry, Thomas L., and Klion, Franklin M. Guide to Liver Transplantation. New York: IgakuShoin, 1992. 334 p.

The Mount Sinai Medical Center liver transplantation program produced this work. Its 17 chapters include discussion of legal and ethical issues, allocation of the donor liver, and evaluation of the prospective recipients - including psychiatric, social, and medical criteria.
Feiden, Karyn, and Rogut, Lynn. Transplantation and Organ Procurement: Past Experiences, Emerging Challenges. New York: United Hospital Fund of New York, 1992. 26 p.

Based on a conference cosponsored by the New York Center for Liver Transplantation, Inc., the New York Regional Transplant Program, and the United Hospital Fund of New York, the paper includes discussion of both national and regional organ allocation.

Foster, Preston F., and Burck, Russell. Moral Entrepreneurship in Donor Liver Allocation. Professional Ethics 2(1 \& 2): 129-39, SpringSummer 1993.

The authors look at the possibility that the emergency nature of a patient's need could be misrepresented in order to receive an organ sooner. They call this "aggressive advocacy," "competitive advocacy," or "moral entrepreneurship," and say it adds a fiduciary role to the physician-patient relationship. Foster and Burck urge public discussion of the issues and an appeal to the character, virtue, and self- discipline of individual physicians.

Jarvis, Rupert. Join the Club: A Modest Proposal to Increase Availability of Donor Organs. Journal of Medical Ethics 21(4): 199-204, August 1995.

Jarvis thinks traditional approaches to obtain more organs are ineffective and proposes that "admission to future transplant lists be conditional on registration as a potential organ donor ...." In the event of any over supply of organs in the future, he suggests that it might be fair for individuals who had not registered but were in need of a transplant to be considered, as long as those registered received first refusal.

Kjellstrand, Carl M., and Dossetor, John B., editors. Ethical Problems In Dialysis And Transplantation. Dordrecht, The Netherlands: Kluwer Academic Publishers, 1992. 235 p.

The editors divide the collection into four sections: principles, selection for treatment and commercialization, stopping treatment (including religious, legal, and ethical aspects), and different views from different countries.

Kluge, Eike-Henner. An Ethicist's Perspective: Designated Organ Donation. BC Medical Jour- 
nal 29(11): 672-74, November 1987.

The author explains designated recipient transplantation as a system that ties access not to need, but to public relations skills or financial capabilities, singling out individuals exempt from considerations of equality and justice. $\mathrm{He}$ urges the medical community to reject designated donation as being outside the otherwise equitable process of allocation, even though it may be an individual donor's right.

Kolata, Gina. Getting on a Transplant List Is the First of Many Hurdles. New York Times, 10 June 1995, p. 1, 29.

Kolata writes that ethicists and transplant surgeons, those she refers to as experts, say that getting on a list is the difficult step and can depend on social circumstances, psychological profile, finances, and the ability to "manipulate the organ transplant system." She goes on to describe the steps involved in having a person placed on the waiting list. A patient must have a doctor who will refer the patient to a transplant center. This includes finding those centers where the patient fits the criteria used. In addition, the patient must have the ability to pay, in some manner, for the costs of evaluation (an estimated \$10,000-\$20,000), for transplantation surgery and care (estimated at $\$ 100,000$ to $\$ 200,000)$, and for ongoing anti-rejection drugs (estimated to be $\$ 1,000$ per month for life).

Kolata, Gina. Long Waiting Lists for Organs Make Ethical Calls Tough. New York Times, 18 October 1992, p. E6.

Describing dilemmas created by scarcity, Kolata comments on the use of operations to implant artificial or animal organs, which then moves these patients to the top of the waiting list for human transplantation.

Kubo, Spencer H.; Ormaza, Sofia M.; Francis, Gary S.; et al. Trends in Patient Selection for Heart Transplantation. Journal of the American College of Cardiology 21(4): 975-8 1, 15 March 1993.

The study looks at outcomes of patient referrals and the utility of selection criteria for heart transplantation. Of 511 referrals, 222 (43\%) were rejected, 39 (8\%) died before evaluation, and $221(43 \%)$ were accepted on the waiting list. From the list 115 (52\%) received trans- plants, $50(22 \%)$ died while waiting, $12(5 \%)$ improved and were taken off the list, $9(4 \%)$ were moved to another program, and 35 (16\%) remained on the list.

Lowy, Frederick, and Martin, Douglas. Ethical Considerations in Transplantation. In Psychiatric Aspects of Organ Transplantation, pp. 108-20. New York: Oxford University Press, 1992.

The authors discuss favorable benefit-to-risk ratio of organ transplant recipients, informed consent, quality of life, selection for treatment, and commercial aspects of organ transplantation.

Madden, B. P., and Geddes, D. M. Which Patients Should Receive Lung Transplants? Monaldi Archives for Chest Disease 48(4): 346-52, August 1993.

Explaining the clinical background of transplantation, the authors provide guidelines and say that careful assessment is vital so that those most likely to benefit are selected. They urge research in the development of xenografting to increase the number of patients able to receive lung transplants.

Menzel, Paul T. Rescuing Lives: Can't We Count? Hastings Center Report 24(1): 22-23, January-February 1994.

Menzel raises the question of fairness, given organ scarcity, when one very sick child receives seven organs therefore denying many other children a chance. He says that nearly half of the children on waiting lists die before they can be transplanted. The idea that multiple need is more medically urgent strikes Menzel as odd, somehow tying the difficulty of the procedure to need. He says "It has ominous implications for the distribution of other scarce health care resources."

Michaels, Marian G.; Frader, Joel; and Armitage, John. Ethical Considerations in Listing Fetuses as Candidates for Neonatal Heart Transplantation. Journal of the American Medical Association 269(3): 401-3, 20 January 1993.

The authors discuss deliberate preterm delivery for the purpose of neonatal cardiac transplantation, noting competition for scarce human hearts between live-born infants and unborn fetuses. They think that it is feasible to offer cardiac 
transplantation as an option for a mother and that her informed consent must be uncoerced.

Miller, Tracy E. Multiple Listing for Organ Transplantation: Autonomy Unbounded. Kennedy Institute of Ethics Journal 2(1); 43-59, March 1992.

Miller explores the social and ethical issues raised by multiple listing when patients seek treatment at several organ transplant centers, thereby gaining access to numerous waiting lists and maximizing access to scarce organs. She discusses national policy and entitlement to health care, concluding that multiple listing is unfair and should be prohibited.

Mudge, Gilbert H.; Goldstein, Sidney; Addonizio, Linda J.; et al. Task Force 3: Recipient Guidelines/Prioritization. Journal of the American College of Cardiology 22(1): 21-31, July 1993.

The group report discusses current medical indications for heart transplantation, limitations of medical indications, indications for retransplantation, recommendations for objective recip-ient criteria, recipient priority for heart transplantation, and limits of prioritization.

O'Connell, Dolores A. Ethical Implications of Organ Transplantation. Critical Care Nursing Quarterly 13(4): 1-7, February 1991.

O'Connell says that the advocacy role of nurses calls for responsible decision making when complex organ transplantation issues raise difficult ethical situations. She calls for a strong nurse-patient relationship to keep the patient fully informed.

Organ and Tissue Transplants: I. Medical Overview, Calvin R. Stiller; II. Sociocultural Aspects, Renée C. Fox and Judith P. Swazey; and III. Ethical and Legal Issues, Arthur L. Caplan. In Encyclopedia of Bioethics, Revised Edition, ed. Warren T. Reich, pp. 1871-94. New York: Macmillan/Simon and Schuster, 1995.

In Part I the historical background of organ transplantation is presented including information about retrieval, preservation, rejection and immunosuppression, success rates, costs, and reimbursement. Part II offers discussion of obligations inherent in giving and receiving organs and the gift concept. Part III provides information about macroallocation and morality and the problems inherent in scarcity of organs.

Peterson, Ronnie. An Emerging Cancer Risk: Organ Transplantation. Cancer Nursing 16(6): 468-72, December 1993.

Peterson says that increased survival in organ transplant recipients places patients at increased risk of developing cancer due to longevity. She uses ethical principles to discuss informed consent, the possibility of "trading one lethal disease for another," and whether oncology nurses are trained to take care of transplant patients.

Ramsey, Paul. Scarce Medical Resources. Columbia Law Review 69(4): 620-92, April 1969.

In this early discussion concerned with the allocation of medical resources including organs, Ramsey holds that "the proper starting point for a rule of final selection is first-come, first- treated."

Rettig, Richard A. The Politics of Organ Transplantation: A Parable of Our Time. Journal of Health Politics, Policy and Law 14(1): 191-227, Spring 1989.

Rettig looks at the historical and political aspects of organ transplantation including the role of the media, financing, distributive justice, and rationing of scarce health resources. He urges a binding budget to allocate funds away from expensive medical procedures that benefit the few toward basic services that benefit the many.

Turcotte, J. G.; Benjamin, M.; Caplan, Arthur L.; et al. Patient Selection Criteria in Organ Transplantation: The Critical Questions. Transplantation Proceedings 21(3): 3377-3446, June 1989.

A special section of the journal offers 18 presentations made at a conference sponsored by the University of Michigan and the Transplant and Health Policy Center in Ann Arbor. Topics included are: value conflicts, policy and criteria problems in allocation, equity in distribution, changes in the waiting line, social factors affecting patient selection, racial issues, money considerations, nonresident access to organs, and the point system for choosing transplant recipients.

Twillman, Robert K.; Manetto, Corinne; Wellisch, 
David K.; and Wolcott, Deane L. The Transplant Evaluation Rating Scale: A Revision of the Psychosocial Levels System for Evaluating Organ Transplant Candidates. Psychosomatics 34(2): 149-53, March-April 1993.

Saying that psychosocial criteria play an important role in evaluating transplant candidates, the authors looked at 10 psychosocial aspects-e.g. presence of a psychiatric disorder, coping resources and strengths, or history of compliance - and found their evaluation a "promising instrument for transplant candidate selection as well as a valuable tool for further research."

[UNOS] Committee Reports. Ethics. UNOS Update 11(8): 22, August 1995. Membership. UNOS Update 11(8): 26-28, August 1995.

Various subjects of ethical interest were presented by ethics committee chair, John $\mathrm{H}$. Sadler, at the annual meeting of UNOS' Board of Governors in Washington, D.C., June 1995.

UNOS Histocompatibility Committee. The National Kidney Distribution System: Striving for Equitable Use of a Scarce Resource. [White Paper]. UNOS Update 11(8): 31-32, August 1995.

The committee explains the background, criteria, and various statistics connected with cadaveric kidney transplantation in the United States.

\section{PHILOSOPHICAL LITERATURE}

Booker, Michael James. Justice and the Macroallocation of Human Donor Organs. Ann Arbor, MI: University Microfilms International, 1991. $167 \mathrm{p}$.

Booker examines the history of the distribution of human body parts, particularly blood allocation, and then explains UNOS distribution policies. He considers eight possible systems of just allocation, advocating a theory of "modified altruistic reciprocity" whereby only those willing to donate organs would be considered for organ transplants.

Rhodes, Rosamond. A Review of Ethical Issues in Transplantation. Mount Sinai Journal of Medicine 61(1): 77-81, January 1994.

Rhodes thinks that unavoidable characteristics of the transplant surgeon's practice require difficult moral judgments. She outlines key ethical issues in procurement and allocation, including organ sales, distributive justice, possible exclusion of free rider recipients (persons unable or unwilling to donate), research, and duties and debts.

Smart, Brian. Fault and the Allocation of Spare Organs. Journal of Medical Ethics 20(1): 26-30, March 1994.

Smart urges that "rectificatory justice" replace distributive justice in access to scarce organs for transplantation. The faultless would be given priority over those who choose self-inflicted harm; this non-punitive restoration would be "akin to reparation in civil law, not criminal law." He concludes that "this would be just only within a framework of robust preventive medicine ...."

Spicker, Stuart. The Search for Bioethical Criteria to Select Renal Transplant Recipients. APA Newsletter on Philosophy and Medicine 91(1): 140-43, Spring 1992.

Whether "objective criteria can be discovered (created?) through bioethical/philosophical analysis such that any renal transplant center can achieve a social consensus that morally justifies the initial selection of recipients for a kidney transplant" is pondered by Spicker here. $\mathrm{He}$ discusses norms, bioethical principles, ethical criteria, and the point system, and urges care in the consideration of "objective medical criteria."

Swazey, Judith P.; and Fox, Renée C. Allocating Scarce Gifts of Life. Trends in Health Care, Law \& Ethics 8(4): 29-34, Fall 1993.

Commenting that human organs are not just like any other commodity, Swazey and Fox point out the enormous symbolic meaning in giving or receiving transplants. They discuss ethical dilemmas concerned with commercialization, multiple transplants, public anxiety over possible favoritism in allocation, the stress placed on limited funds by expensive transplants, and rationing health care.

\section{INSTITUTIONAL AND PUBLIC POLICY ISSUES}

- General 
American Medical Association. Council on Ethical and Judicial Affairs. Ethical Considerations in the Allocation of Organs and Other Scarce Medical Resources Among Patients. Report 49. Code of Medical Ethics Reports 4(2): 140-73, July 1993. (See also Archives of Internal Medicine 155(1): 29-40, 9 January 1995).

Indicating both appropriate and inappropriate procedures for applying criteria to allocate organs, the Council suggests that UNOS consider making changes in six areas of current policy: quality of life issues should be addressed, less emphasis should be placed on medical emergency, the amount of resources required should be noted, a change should be made in methods used to place patients on the waiting list, geographic priorities should be prohibited, and a single national list for each type of organ should be instituted.

Bronsther, Oscar; Fung, John J.; Isakis, Andreas; et al. Prioritization and Organ Distribution for Liver Transplantation. Journal of the American Medical Association 271(2): 140-43, 12 January 1994.

The authors looked at 124 cases of adults and children who received livers between 1984 and 1992. They suggest that restoration of a "meaningful quality of life" and degree of urgency are all necessary parts of providing liver transplantation services. They express concern about wasting scarce livers in cases with no chance of recovery or for persons without present need for the therapy.

Burdick, James F. Potential Conflicts of Interest Generated by the Use of Non-Heart Beating Cadavers. Kennedy Institute of Ethics Journal 3(2): 199-202, June 1993.

Burdick, a former chairman of the UNOS Ethics Committee, raises questions about the use of non-heart-beating cadavers, saying that the organs might not be entered in the pool by the retrieving institution. He thinks UNOS should develop a method to monitor distribution of such organs to assure that local centers do not have an unfair advantage.

Childress, James F. Policies for Allocating Organs for Transplantation: Some Reflections. Biolaw 11(3 \& 4): S:29-S:39, March-April 1995.
Looking back on 25 years of intense interest in organ transplantation, Childress presents current allocation processes and makes suggestions for future modification to achieve greater equity. He includes the UNOS Statement of Principles and Objectives of Equitable Organ Allocation.

Dickens, Bernard M. Ethics Committees, Organ Transplantation and Public Policy. Law, Medicine \& Public Policy 20(4): 300-6, Winter 1992.

Dickens thinks that an ethics committee that is advising or making policy about organ transplantation needs clinical specialists on the committee or access to information resources. $\mathrm{He}$ discusses both criterion- and non-criterion-based organ allocation, saying that committees may adopt different approaches but should disclose their reasoning since such decisions carry great weight.

Lawry, Kathleen. Grappling with Ethical Issues in Solid Organ Transplantation Cases. HEC Forum 6(1): 47-56, January 1994.

Lawry notes that UNOS' goal is to ensure the fair distribution of organs for transplant, but that various agencies set policy. She includes Medicare (which has regulations), insurance payers (who develop their own criteria), and most states (which have a consortium to set policy and review cases at state institutions). Lawry describes selection guidelines at the Cleveland Clinic Foundation and presents two case studies.

Margolis, Robin Elizabeth. Are Transplanted Organs Being Allocated Unfairly and Illegally? HealthSpan 10(6): 14-17, June 1993.

Margolis provides a description of the organ allocation system and discusses a Government Accounting Office report which found discrepancies in organ allocation policy. She notes recommendations have been made to have more information from transplant recipients made available to both the OPOs and UNOS.

Moskowitz, Ellen. In the Courts: Livers. Hastings Center Report 25(4): 48, July-August 1995.

Four cases concerning liver transplants that were denied based on the high costs of the procedure are described: two state Medicaid 
denials that were reversed in court, an HMO denial, and a widow who sued the hospital that would not admit her husband without insurance coverage.

Prottas, Jeffrey. The Ethics and Politics of Distribution. In The Most Useful Gift: Altruism and the Public Policy of Organ Transplants, Chapter 5, pp. 115-53. San Francisco: Jossey-Bass Publishers, 1994.

Prottas calls organ distribution a zero-sum game affecting not only patients waiting for transplants, but also transplant surgeons whose quantity and character of work depends upon receiving organs for their patients. He discusses both public policy issues and local medical politics related to organ allocation, noting that organ allocation policy has moved from the transplant community to the government. "Physicians dominate the debate through knowledge as well as power, but they must justify their actions now as trustees of the public."

United Network for Organ Sharing. [UNOS]. Articles of Incorporation of United Network for Organ Sharing. 3 November 1994.

The document contains the by-laws (including criteria for institutional membership), standards for testing and typing of organ recipients, UNOS policies for OPOs, and UNOS registration forms.

\section{- Rationing}

Rhodes, Rosamond; Miller, Charles; and Schwartz, Myron. Transplant Recipient Selection: Peacetime vs. Wartime Triage. Cambridge Quarterly of Healthcare Ethics 1(4): 327-31, Fall 1992.

The authors recommend that organs be allocated by the concept of "wartime triage": salvage those persons who are most likely to benefit from intervention and leave the most critically injured, who have little hope of survival, to die. They say it provides a rational foundation for modifying current policy, is grounded in reality, and offers promise of improved outcome while remaining just and equitable.

Stevenson, Lynne Warner; Warner, Stanley L.; Steimle, Anthony E. et al. The Impending Crisis
Awaiting Cardiac Transplantation: Modeling a Solution Based on Selection. Circulation 89(1): 450-57, January 1994.

In view of the scarcity of hearts, the authors suggest reducing the number of candidates waiting for heart transplants by lowering the age limit to 55, which they say would reduce the list by 30 percent and improve survival for those remaining on the list. They also recommend that listed persons should have an 80 percent risk of dying without transplantation, noting that many persons are listed for a long time, even though stable, in order to build waiting time.

Surman, Owen S., and Purtilo, Ruth. Reevaluation of Organ Transplantation Criteria: Allocation of Scarce Resources to Borderline Candidates. Psychosomatics 33(2): 202-12, Spring 1992.

The authors introduce four suggestions that decision makers could use to either include or exclude marginal candidates for organ transplantation: the physician's interpretation of beneficent advocacy-i.e., the patient's chance of a longer and more active life - the patient's or surrogate's wishes; cost-benefit considerations; and the need for research to improve scientific understanding of transplantation issues. They discuss an ethical approach to support each suggestion.

\section{- Retransplantation}

Collins, Eileen G., and Mozdzierz, Gerald J. Cardiac Retransplantation: Determining Limits. Heart and Lung 22(3): 206-12, May-June 1993.

Examining cardiac retransplantation decisions, the authors find a lower survival rate for retransplant patients. Questions of justice and fairness arise when donor hearts are scarce; second and third transplants in the same patient deprive those who have not had a first opportunity for transplantation. They conclude that transplantation is a "one-time treatment option" and that retransplantation should not be allowed.

Delmonico, Francis L.; Tolkoff-Rubin, Nina; Auchincloss, Hugh; et al. Second Renal Transplantations: Ethical Issues Clarified by Outcome: Outcome Enhanced by a Reliable 
Crossmatch. Archives of Surgery 129(4): 354-60, April 1994.

The authors reviewed the initial and long-term outcomes of second-time renal transplant recipients and found that excellent survival is attainable. They say that "restricting suitable patients to subsequent lifelong dialysis becomes unethical."

Self, Donnie J., and Olivarez, Margie. The Influence of Gender on Conflicts of Interest in the Allocation of Limited Critical Care Resources: Justice Versus Care. Journal of Critical Care 8(1): 64-74, March 1993.

Self and Olivarez analyze the concepts of justice and of care as alternative solutions to moral problems found in repeat organ transplantations in one recipient. They utilize moral theories developed by Lawrence Kohlberg and Carol Gilligan, and conclude that when women use justice to resolve moral dilemmas "they do a better job of it than men."

Ubel, Peter A.; Arnold, Robert M.; and Caplan, Arthur L. Rationing Failure: The Ethical Lessons of the Retransplantation of Scarce Vital Organs. Journal of the American Medical Association 270(20): 2469-74, 24 November 1993. Retransplantation of Scarce Organs: The Ethical Lessons. Letters. Journal of the American Medical Association 271(15): 1157-58, 20 April 1994.

Despite an organ shortage, retransplantation is not used as a criterion to distribute organs according to the authors, who examine three differences between primary and subsequent transplants: (1) obligations of the transplant teams to their patients; (2) fairness of allowing some multiple transplants while others die waiting for a first transplant; and (3) any differences in efficacy between the two. They found that primary transplants should receive priority based on lower mortality after transplantation and recommend a change in the allocation system to reflect this.

\section{SPECIAL POPULATIONS}

\section{- General}

Ayres, Ian; Dooley, Laura G.; and Gaston, Robert
S. Unequal Racial Access to Kidney Transplantation. Vanderbilt Law Review 46(4): 805-63, May 1993.

Kidney allocation plans based on antigen matching rules make it more difficult for black patients to qualify for transplantation, according to the authors who say that white dialysis patients have a 50 percent greater chance of receiving a kidney. They urge a change in the allocation of points since new immunosuppressants reduce the impact of antigen matching, thus making current rules outdated.

Cohen, Robert L., and Paul, Jeffrey. A Prisoner in Need of a Bone Marrow Transplant. Case Study. Hastings Center Report 17(5): 26-27, October-November 1987.

A prisoner serving a third-degree murder sentence is considered for early release for a bone marrow transplant (at public expense) for leukemia. Prison officials prefer to release him because they cannot afford the cost of surgery. Cohen thinks parole should be based on the prisoner's prognosis and debilitation, so that the prisoner can receive the transplant if clinically indicated. Paul says denial of liberty and partial surrender of rights precludes a criminal's entitlement to publicly funded treatment.

Gaston, Robert S.; Ayres, Ian; Dooley, Laura G.; et al. Racial Equity in Renal Transplantation: The Disparate Impact of HLA-Based Allocation. Journal of the American Medical Association 270(11): 1352-56, 15 September 1993. [Also, Norman, Douglas J. Racial Inequities in Kidney Transplantation: The UNOS Perspective. Letter. Journal of the American Medical Association 271(18): 1402-03, 11 May 1994.]

One-third of those awaiting kidney transplants are African Americans, who comprise 12 percent of the country's population. The authors contend that all suitable renal transplant candidates should have equitable access to cadaveric kidneys, calling HLA-based allocation simplistic in assuming that "universal benefit will result from better matching." Douglas Norman of the National Organ Procurement and Transplantation Network defends the 1994 system as equitable, pointing out that many factors are used for kidney 
allocation. [Since 1994, UNOS has changed the allocation formula in order to improve African-American access.]

Kasiske, Bertram L.; Neylan, John F.; Riggio, Robert R.; et al. The Effect of Race on Access and Outcome in Transplantation. New England Journal of Medicine 324(5): 302-7, 31 January 1991.

The Patient Care and Education Committee of the American Society of Transplant Physicians examined the issue of racial inequality in transplantation. The committee found that while end-stage renal disease is more common in racial minorities, fewer African-Americans (who have a lower survival rate than the others), Hispanics, or Asians undergo kidney transplantation. The committee recommends that health care providers "increase their advocacy role to assist patients in obtaining the suitable form of treatment. This duty is greater for advocates of patients ill equipped to understand, accept, or comply with the complicated issues of transplantation and its follow-up."

Randall, Ten. The Gender Gap in Selection of Cardiac Transplantation Candidates: Bogus or Bias? Journal of the American Medical Association 269(21): 2718, 2720, 2 June 1993.

Of the 2,700 cardiac transplants worldwide in 1992, 81 percent were to men. Randall writes that women often decide against surgery prior to listing or take their names off the list, they are often older when the need develops, their insurance status may be an issue (particularly with respect to Medicaid not covering follow-up services and immunosuppressive therapy), and referring physicians may be biased toward choosing men.

Shaw, Byers W. Transplantation in the Elderly Patient. Surgical Clinics of North America 74(2): 389-400, April 1994.

Establishing upper age limits for transplant recipients of various organs remains an elusive task according to Shaw. He says that over a ten-year period, upper limits have moved from age 40 or 50 into the $70 \mathrm{~s}$. He says enthusiasm to demonstrate skill in treating the aged should be tempered by understanding the shortage of available donors and the number of life years saved, and urges responsible stewardship of both organs and health care dollars.

Takemoto, Steve; Terasaki, Paul L.; Gjertson, David W.; et al. Equitable Allocation of HLA-Compatible Kidneys for Local Pools and for Minorities. New England Journal of Medicine 331(12): 760-64, 22 September 1994.

The authors evaluated a new HLA-matching method that could alleviate criticisms that the selection method used by UNOS to allot cadaveric kidneys was unfair to minorities. They suggest that by inserting two new matching categories in the point system, the number of patients with matches would increase.

Veatch, Robert M. Equality, Justice, and Rightness in Allocating Health Care: A Response to James Childress. In A Time To Be Born and a Time To Die: The Ethics of Choice, ed. Barry S. Kogan, pp. 205-16. Hawthorne, NY: Aldine De Gruyter, 1991.

The author comments on the Childress essay in the same book and discusses his views of justice in organ allocation theory. Under current allocation practices, he says the arbitrary assignment of points to criteria for kidney allocation results in "blacks and Hispanics ... not being able to get points."

Yuan, Ufei; Gafni, Amiram; Russell, J. David; et al. Development of a Central Matching System for the Allocation of Cadaveric Kidneys: A Simulation of Clinical Effectiveness Versus Equity. Medical Decision Making 14(2): 124-36, April-June 1994.

The authors set out to develop a computer simulation to study the impact of using different equity criteria to allocate kidneys. They say that final choice about any allocation algorithm requires a value judgment, "i.e. how great a reduction in HLA-match score should be traded in order to improve equity score (or vice versa)." They think that such a model is feasible.

Zachary, Andrea A. Is There Racial Bias in Transplantation? Editorial. Journal of the National Medical Association 85(11): 821-23, November 1993.

Zachary says that African Americans comprise 
almost one-third of the waiting list but only receive one-fourth of the cadaveric renal transplants.

\section{- Celebrities}

Colburn, Don. Gov. Casey's Quick Double Transplant: How Did He Jump to the Top of the Waiting List? Washington Post Health 9(25): 8-9, 22 June 1993.

Saying the average wait for a heart is 198 days, Colburn writes that Governor Robert Casey of Pennsylvania received both a heart and lung less than 24 hours after his need was noted, the oldest American to have done so. University of Pittsburgh surgeon Thomas Starzl is cited as indicating that the priority was given because the patient needed double organs and no one else was on such a waiting list.

Trafford, Abigail. Sick Celebrities and Our Common Lot. Washington Post Health 11(25): 6, 20 June 1995.

The author calls attention to media coverage received by famous patients and concludes such patients are needed to educate the public and raise "the key question" of what basis should be used if medical care must be rationed.

\section{- Foreign Nationals}

Davis, Dena S. Organ Transplants, Foreign Nationals, and the Free Rider Problem. Theoretical Medicine 13(4): 337-47, December 1992.

Davis describes 'free riders' as persons who are not members of the community that provides organs and who would not be eligible recipients. She examines philosophical arguments and concludes that it would be unfair to deny foreigners, suggesting an arbitrary quota system as an ethical solution.

Gottleib, Lawrence, and Zucker, Mark J. Organs for Undocumented Aliens? A Transplantation Dilemma. Cambridge Quarterly of Healthcare Ethics 4(2): 229-38, Spring 1995.

Newark Beth Israel Medical Center, the sole provider of heart and lung transplantation in New Jersey, follows the UNOS guidelines for recipient selection, which do not mention illegal aliens. The Newark institution decided that it could not be responsible for subsidizing the care of an undocumented foreign citizen who does not meet the eligibility for "healthcare entitlement funds" unless the patient can produce a deposit sufficient to cover all projected cost.

\section{- Lifestyle}

Allen v. Mansour. 681 F.Supp 1232 (E.D. Mich. 1986).

The Court found that "the liver transplant procedure is medically necessary. While the Court cannot determine Allen's medical suitability for transplant, the Court finds that the two-year abstinence requirement is arbitrary and unreasonable as formulated and applied." The Court ordered the defendants to approve Medicaid funding of the liver transplant.

Caplan, Arthur L. Ethics of Casting the First Stone: Personal Responsibility, Rationing, and Transplants. Alcoholism: Clinical and Experimental Research 18(2): 219-21, March-April 1994.

The author writes that there is an increasing interest in changing the obligation to heal regardless of the character or conduct of the patient. He thinks that none of the arguments about an alcoholic's personal responsibility are persuasive; the "data are not ambivalent: those whose livers fail as a result of alcohol abuse can do about as well as others whose livers fail for other reasons." He urges care that sin not become a test of who will live or die.

Cohen, Carl; Benjamin, Martin; and the Ethics and Social Impact Committee of the Transplant and Health Policy Center, Ann Arbor, MI. Alcoholics and Liver Transplantation. Journal of the American Medical Association 265(10): 1299-1301, 13 March 1991. (See Moss, Alvin, and Siegler, Mark.)

The authors hold that alcoholics should not be precluded from liver transplantation since there is no good moral or medical reason to do so, and it is unjust to "implement categorical preclusion simply because others might respond negatively."

Goodstein, Laurie. Crying Foul Over Mantle: Liver Transplant Sparks Ethics, Alcoholism 
Debate. Washington Post 10 June 1995, pp. B1, B3.

The reporter notes the debate over the nature of alcoholism, and cites Robert M. Veatch, a member of the UNOS ethics panel, who says that the panel was split when it tried to decide the question of whether a history of alcohol abuse should count against those needing transplants. He said the surgeons generally did not think that alcoholism should be taken into account, while others on the panel felt that perhaps those who had not engaged in destructive behavior should receive a few extra points which would be useful in tie breaking between possible recipients. Veatch is quoted as saying "I think that at least adults bear some degree of responsibility if they've made voluntary choices that risk their health."

Kluge, Eike-Henner. Drawing the Ethical Line Between Organ Transplantation and Lifestyle Abuse. Canadian Medical Association Journal 150(5): 745-46, 1 March 1994.

The author thinks lifestyle considerations are an appropriate reason to refuse organ transplantation. Kluge writes that no one has control over genetic inheritance or, usually, accidents, but one knows that the adoption of an unhealthy lifestyle can lead to injury and need for health care. He uses smokers as an example of those making an irresponsible decision; to insist that they be treated like nonsmokers is to "unjustly treat irresponsible people the same as responsible people." He cites Canadian Health Care Management Dispatch DP 53.2 (1990), where University Hospital in London, Ontario, places alcoholics at the bottom of the guidelines list when allocating livers; Kluge says others should "follow suit."

Moss, Alvin H., and Siegler, Mark. Should Alcoholics Compete Equally for Liver Transplantation? Journal of the American Medical Association 265(10): 1295-98, 13 March 1991. (See Cohen, Carl, et al.)

The authors recommend that patients who develop end-stage liver disease through no fault of their own should have a higher priority for receiving a transplant than those whose disease results from failure to obtain treatment for alcoholism. They base their proposal on fairness and whether public support for liver transplantation can be maintained if those with alcohol related disease receive more than half of the donor livers.

Paris, W.; Muchmore, J.; Pribil A.; et al. Study of the Relative Incidences of Psychosocial Factors Before and After Heart Transplantation and the Influence of Postransplantation Psychosocial Factors on Heart Transplantation Outcome. Journal of Heart and Lung Transplantation 13(3): 424-32, May-June 1994.

The authors look at substance abuse, noncompliance, psychiatric problems, and obesity in relation to outcome 18 months after heart transplantation. They found that patients who were abusing substances may abstain after transplantation but have other psychosocial problems, while the presence of psychiatric problems or noncompliance before transplantation continues after transplantation, increasing readmissions and costs.

Sorrell, Michael F.; Zetterman, Rowen K.; and Donovan, Jeremiah P. Alcoholic Hepatitis and Liver Transplantation: The Controversy Continues. Alcoholism: Clinical and Experimental Research 18(2): 222-23, March-April 1994.

The authors discuss concerns about recidivism in alcoholics who receive new livers.

Trafford, Abigail. New Livers for Hard Livers? Washington Post Health 10(47): 6, 29 November 1994.

Trafford says there are not enough organs available for those who need them and discusses the pros and cons of allocation to those persons whose habits or addictions caused the need.

This Scope Note was prepared by Pat Milmoe McCarrick, M.L.S., a Reference Librarian at the National Reference Center for Bioethics Literature. Literature available through September 1995 is represented in this Scope Note. 